\title{
Longitudinal Health Status from Early Disease to Adulthood and Associated Prognostic Factors in Juvenile Idiopathic Arthritis
}

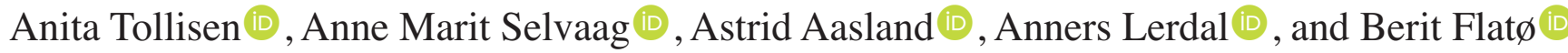

ABSTRACT. Objective. To describe the longitudinal health status from childhood to adulthood in patients with juvenile idiopathic arthritis (JIA), compare outcomes after 19 years with those of controls, and identify early predictors of physical functioning, pain, and physical health-related quality of life (HRQOL).

Methods. Between 1995-2003, 96 patients with JIA (mean $6.1 \pm 4.0 \mathrm{yrs,} 67 \%$ female) were assessed within 18 months of diagnosis and every 6 months for the next 3 years with measures of JIA disease activity, physical functioning, pain, fatigue, and well-being. They were reassessed a mean of $18.9 \pm$ 1.5 years later (mean age $25.1 \pm 4.2 \mathrm{yrs}$ ) with measures of physical disability [Health Assessment Questionnaire-Disability Index (HAQ-DI)], pain, fatigue, well-being (visual analog scale), and physical and mental health-related quality of life (HRQOL; Medical Outcomes Study 12-item Short Form Health Survey, version 2).

Results. During the first 3 years, physical disability improved $(\mathrm{p}<0.001)$ and the proportion of patients reporting best possible well-being increased $(\mathrm{p}=0.013)$, while pain and fatigue did not change. At 3- and 19-year followups, patients had similar levels of physical disability, well-being, and pain, but fatigue increased $(\mathrm{p}=0.016)$ and the number of patients with HAQ-DI $=0$ decreased $(\mathrm{p}=0.001)$. After 19 years, patients had worse pain and physical HRQOL than controls $(\mathrm{p}<0.001)$. Pain, active joints, and physical disability during the first 3 years were associated with more disability and pain and worse physical HRQOL after 19 years ( $p<0.001-0.047)$.

Conclusion. Patients with JIA reported similar physical functioning, well-being, and pain at 3- and 19-year followups, but more fatigue after 19 years. Patients also had worse health status than controls after 19 years. Pain, active joints, and physical disability were early predictors of unfavorable outcomes. (First Release July 1 2019; J Rheumatol 2019;46:1335-44; doi:10.3899/jrheum.180948)

Key Indexing Terms:

JUVENILE IDIOPATHIC ARTHRITIS PAIN

HRQOL

\section{PHYSICAL DISABILITY}

ADULTS

From the Unger-Vetlesens Institute, Lovisenberg Diaconal Hospital; Department of Rheumatology, Oslo University Hospital, Rikshospitalet; Institute of Clinical Medicine, Faculty of Medicine, University of Oslo; Section of Psychosomatics and CL-Child Psychiatry, Department of Clinical Neurosciences for Children, Division of Paediatric and Adolescent Medicine, Oslo University Hospital, Rikshospitalet;

Department of Patient Safety and Research, Lovisenberg Diaconal Hospital; Department of Nursing Science, Institute of Health and Society, Faculty of Medicine, University of Oslo, Oslo, Norway.

This project was supported by the Norwegian Foundation for Health and Rehabilitation.

A. Tollisen, RN, MNSc, From the Unger-Vetlesens Institute, Lovisenberg Diaconal Hospital, and Department of Rheumatology, Oslo University Hospital, Rikshospitalet, and Institute of Clinical Medicine, Faculty of Medicine, University of Oslo; A.M. Selvaag, MD, PhD, Department of Rheumatology, Oslo University Hospital, Rikshospitalet; A. Aasland, MD, $P h D$, Section of Psychosomatics and CL-Child Psychiatry, Department of Clinical Neurosciences for Children, Division of Paediatric and Adolescent Medicine, Oslo University Hospital, Rikshospitalet; A. Lerdal, RN, PhD, Department of Patient Safety and Research, Lovisenberg Diaconal Hospital, and Department of Nursing Science, Institute of Health and Society, Faculty of Medicine, University of Oslo; B. Flat $\phi, M D, P h D$, Department of Rheumatology, Oslo University Hospital, Rikshospitalet, and Institute of Clinical Medicine, Faculty of Medicine, University of Oslo. Address correspondence to A. Tollisen, Department of Rheumatology, Oslo University Hospital, Rikshospitalet, Postboks 4950, Nydalen, 0424 Oslo, Norway.E-mail: atol@lds.no

Accepted for publication February 13, 2019.
About $40-60 \%$ of patients with juvenile idiopathic arthritis (JIA) have continuous or recurrent disease activity extending into adulthood ${ }^{1,2,3,4}$. An important goal in the treatment of JIA is for patients to grow up to have the best possible quality of life. Health-related quality of life (HRQOL) is often measured through individuals' subjective appraisals of their physical and psychosocial health, as defined by the World Health Organization ${ }^{5}$.

Physical disability, increased pain and reduced HRQOL have been reported in adults with a history of JIA ${ }^{2,4,6,7,8,9}$. However, the patients participating in these previous studies were diagnosed 1-2 decades before biologic agents were available and early methotrexate (MTX) was rarely used. New studies are needed because changes in treatment options since then may limit their present relevance ${ }^{10,11,12,13}$.

A few previous studies have examined the longterm longitudinal changes in health status among patients with JIA $^{1,2,14,15}$. However, only 1 study included children early in their disease course, and these children were included in $1984-1986^{2}$. Studies have indicated that early control of disease activity leads to better outcomes among children with JIA $^{16,17}$. The identification of early predictors of longterm

Personal non-commercial use only. The Journal of Rheumatology Copyright $\odot$ 2019. All rights reserved. 
outcome into adulthood has been scarce, and only Bertilsson, et al used a prospective design during the early disease course ${ }^{2,3,18,19,20}$. Because different patterns of disease activity early in the disease course have been identified in children with JIA $^{21}$, sequential assessments may increase the predictive ability of the assessed variables. Although longitudinal studies of the early disease course in children with JIA have been performed ${ }^{16,22,23,24}$, the effect of sequential assessment on longterm outcome has not been explored previously.

Pain is a commonly reported symptom of JIA ${ }^{12,25}$. To the best of our knowledge, no study has explored early predictors of pain in adults with a history of JIA. Further, pain intensity at a group level could be masking different pain trajectories within the group. Therefore, longitudinal studies of pain early in the disease course are needed to determine whether they are associated with health status in adulthood.

Given these gaps in the research literature, the objective of our study was to describe the longitudinal changes of health status in patients with JIA from childhood to adulthood, compare health status in adults with JIA to controls from the general population, and identify early predictors. The patients in this study were diagnosed from 1995 to 2000. Although biologic agents were not available at disease course, they became available during the first few years of their disease course. The patients were prospectively followed over 3 years early in the disease course and reassessed after 19 years to provide a greater understanding of the association between early disease course and health status in adulthood.

\section{MATERIALS AND METHODS}

Study population. Patients with JIA and $<18$ months of disease duration were recruited from Oslo University Hospital from April 1995 to December 1999 , examined by a pediatric rheumatologist and assessed by questionnaires every 6 months for the next 3 years, and reassessed 19 years later. The patients were classified according to the International League of Associations for Rheumatology guidelines based on physicians' clinical examinations in the patients' medical records ${ }^{26}$. Disease onset was defined as the day a physician documented symptoms or signs of JIA. Controls matched for age and sex were selected randomly from the National Registry. The patients resided throughout Norway (except the Northern region), whereas controls resided in Oslo and the surrounding county of Akershus, which contains both rural and urban areas.

The Regional Committees for Medical and Health Research Ethics approved the study (approval number 2015/532), and informed consent was obtained in accordance with the Declaration of Helsinki.

Data collection early in the disease course (1995-2003). A rheumatologist examined all patients and information regarding medication was prospectively collected. Patients were assessed using the following indicators of JIA disease activity: physician's global assessment (PGA) of disease activity (5-point Likert scale where $1=$ best possible score), number of joints with active arthritis, number of joints with limited range of motion (LROM), and erythrocyte sedimentation rate (ESR). The Childhood Health Assessment Questionnaire (CHAQ) was used to assess physical disability ${ }^{27}$, and visual analog scales (VAS) were used to assess patients' pain, fatigue, and overall well-being ${ }^{22,28,29}$. All VAS scales in our study were measured on a $10-\mathrm{cm}$ scale where $0=$ best and $10=$ worst possible score. Pain intensity and well-being ratings were obtained from children $\geq 8$ years of age and by proxy reports from parents for children $<8$ years. Fatigue and physical disability (CHAQ) ratings were obtained from children $\geq 12$ years of age and by proxy reports from parents for children $<12$ years. Based on a previous study of adolescent with JIA, pain scores $>3$ were defined as moderate to severe pain $^{25}$.

Data collection at 19-year followup. At 19-year followup, demographic information (age, sex, marital status, occupational status, and highest level of education) was collected from patients and controls. Additionally, HRQOL was assessed with the Medical Outcomes Study 12-item Short Form Health Survey, version 2 (SF-12) including the physical component summary (PCS) and mental component summary (MCS $)^{30}$. Pain severity and pain interference (effect of pain on daily functioning) were assessed with the Brief Pain Inventory (BPI) short form, fatigue with a VAS scale, and signs of anxiety and depression with the Hopkins Symptom Checklist $5^{28,31,32}$. For JIA patients only, physical disability was assessed using the Health Assessment Questionnaire-Disability Index (HAQ-DI), supplemented with VAS ratings of pain intensity and overall well-being 28,33 Information regarding current and previous use of medication and number of active joints was obtained using self-report questionnaires ${ }^{34}$. Questionnaires were delivered and returned by mail.

Statistical analysis. Comparisons between groups were performed using chi-square test of independence, independent sample t test and Wilcoxon-Mann-Whitney test. Independent sample analyses were selected to accommodate missing data without reducing sample size, but paired sample test was also conducted to confirm that the results were similar. Differences between repeated measures were analyzed with 1-way repeated measure ANOVA, Friedman's test of variance, Cochran's Q test, Wilcoxon signed-rank test, and McNemar's test. Linear regression analyses were conducted to identify possible predictors of pain (VAS) and physical HRQOL (SF-12 PCS). Logistic regression analyses were used to assess predictors of physical disability (assessed by HAQ-DI). Independent variables associated with the dependent variable in the univariate analyses $(p<0.10)$ were evaluated in the multivariate analyses (manual backward regression method). BPI ratings of pain severity and pain interference were not included in the regression analyses because of multicollinearity between each other and with VAS pain $(r>0.7)$. Imputation of missing values on continuous variables at 1 - and 3-year followups was performed by median substitution, with $<3 \%$ of the values being replaced.

Growth mixture modeling (GMM) was used to divide individuals into groups based on their trajectory of pain over time. The number of latent classes was decided based on the change in the likelihood function and the proportion of observations in each class. Individuals were assigned to classes based on posterior probabilities, and the discrimination among the classes was found to be clear. The analysis was carried out using the GLLAMM package in Stata. All other statistical analyses were performed using SPSS software Version 22 (IBM Corp.). A 2-tailed p value $<0.05$ was considered statistically significant.

\section{RESULTS}

Demographic variables of patients and controls. Of the 197 patients who participated in the initial study from 1995 to 2003, at the 19-year followup, 4 had died, 1 had been re-diagnosed, 16 could not be located, and 80 patients chose not to participate (Appendix 1). A total of 96 (50\%) of the 192 living patients with JIA agreed to participate in the 19 -year followup and were compared with 96 controls. No significant differences were found between the patients who declined participation, could not be located, or had died, and the participants regarding age at disease onset, sex, polyarticular disease course, and scores on the CHAQ and VAS pain at 3-year followup (data not shown). 
The sample was predominantly female $(67 \%)$ with a mean (SD) age of $6.1( \pm 4.0)$ years at disease onset and $25.1( \pm 4.2)$ years at 19-year followup (Table 1). Educational achievement was similar between the patients and controls, although fewer adults with JIA were in full-time employment/study $(\mathrm{p}=0.036)$ and more were receiving disability or social benefit allowance $(\mathrm{p}=0.005)$.
Health status in patients and controls at 19-year followup. No physical disability (HAQ-DI $=0$ ) was found in 52 patients $(54 \%)$ and severe disability (HAQ-DI $\geq 1.5)$ was found in 3 patients (3\%; Table 2). Moderate to severe pain (VAS pain $>3$ ) was reported by 26 patients $(27 \%)$ and poor overall well-being (VAS well-being $>3$ ) by $26(27 \%)$. More pain and higher effect of pain on daily functioning (BPI pain severity

Table 1. Clinical characteristics of patients and health status and demographic characteristics of patients and controls at 19-year followup.

\begin{tabular}{|c|c|c|c|}
\hline Variables & Patients, $\mathrm{n}=96$ & Controls, $\mathrm{n}=96$ & $\mathrm{p}$ \\
\hline \multicolumn{4}{|l|}{ Demographic characteristics } \\
\hline Sex, female, n (\%) & $64(67)$ & $64(67)$ & $>0.99$ \\
\hline Age, yrs & $25.1(4.2)$ & $25.1(4.2)$ & 0.94 \\
\hline Living alone, with friends, or in a dormitory, $\mathrm{n}(\%)$ & $32(33)$ & $27(28)$ & 0.38 \\
\hline Living with partner and/or children, $\mathrm{n}(\%)$ & $41(43)$ & $47(49)$ & 0.46 \\
\hline Living with parents, $\mathrm{n}(\%)$ & $21(22)$ & $22(23)$ & 0.92 \\
\hline College or university level education, $\mathrm{n}(\%)$ & $42(44)$ & $51(53)$ & 0.17 \\
\hline Full-time study or paid job, n (\%) & $74(77)$ & $85(88)$ & 0.036 \\
\hline Receiving disability or social benefit, $\mathrm{n}(\%)$ & $12(13)$ & $2(2)$ & 0.005 \\
\hline \multicolumn{4}{|l|}{ Clinical characteristics } \\
\hline Disease duration, yrs & $18.9(1.5)$ & & \\
\hline Age at disease onset, yrs & $6.1(4.0)$ & & \\
\hline Disease duration at baseline, mos & $4.4(4.0)$ & & \\
\hline Daily stiffness duration $>10 \min , \mathrm{n}(\%)$ & $44(46)$ & & \\
\hline No. patients with active joints, $\mathrm{n}(\%)$ & $57(59)$ & & \\
\hline No. patients using DMARD & $52(54)$ & & \\
\hline No. patients using biological DMARD & $37(39)$ & & \\
\hline No. patients using methotrexate & $28(29)$ & & \\
\hline No. patients using sulfasalazine & $5(5)$ & & \\
\hline \multicolumn{4}{|l|}{ JIA subtypes (ILAR classification) } \\
\hline Systemic arthritis, n (\%) & $7(7)$ & & \\
\hline Polyarticular RF-negative, n (\%) & $24(25)$ & & \\
\hline Polyarticular RF-positive, n (\%) & $1(1)$ & & \\
\hline Oligoarticular persistent, $\mathrm{n}(\%)$ & $36(38)$ & & \\
\hline Oligoarticular extended, n (\%) & $10(10)$ & & \\
\hline Enthesitis-related arthritis, n (\%) & $5(5)$ & & \\
\hline Psoriatic arthritis, $\mathrm{n}(\%)$ & $4(4)$ & & \\
\hline Undifferentiated arthritis, n (\%) & $9(9)$ & & \\
\hline \multicolumn{4}{|l|}{ Health status in patients and controls } \\
\hline SF-12*, PCS & $49.6(9.8)$ & $56.1(6.3)$ & $<0.001$ \\
\hline Physical functioning & $52.4(7.9)$ & $53.4(7.1)$ & 0.35 \\
\hline Role physical & $49.8(9.1)$ & $54.0(7.4)$ & 0.001 \\
\hline Bodily pain & $48.1(9.8)$ & $55.1(8.9)$ & $<0.001$ \\
\hline General health & $48.5(10.8)$ & $55.1(9.0)$ & $<0.001$ \\
\hline SF-12*, MCS & $48.5(10.0)$ & $48.4(9.2)$ & 0.95 \\
\hline Vitality & $43.3(10.3)$ & $49.2(9.4)$ & $<0.001$ \\
\hline Social functioning & $50.2(8.9)$ & $52.5(7.2)$ & 0.06 \\
\hline Role emotional & $50.8(8.8)$ & $50.2(8.6)$ & 0.64 \\
\hline Mental health & $49.9(9.8)$ & $50.0(9.1)$ & 0.90 \\
\hline BPI, pain severity $(0-10)$, median (range) & $1.25(0-9)$ & $0.75(0-6.8)$ & $<0.001$ \\
\hline BPI, pain interference $(0-10)$, median (range) & $0.57(0-8.4)$ & $0.0(0-9)$ & 0.001 \\
\hline Fatigue (VAS 0-10), median (range) & $2.4(0-10)$ & $1.6(0-8)$ & 0.17 \\
\hline VAS fatigue $>3, \mathrm{n}(\%)$ & $42(42)$ & $24(25)$ & 0.001 \\
\hline SCL-5, (Likert 1-4), median (range) & $1.4(1-4)$ & $1.4(1-3.4)$ & 0.89 \\
\hline
\end{tabular}

Values are mean (SD) unless otherwise indicated. \# Eighteen patients used a combination of 2 DMARD. * Norm-based score (SD): 50 (10). VAS: visual analog scale; DMARD: disease-modifying antirheumatic drugs; JIA: juvenile idiopathic arthritis; ILAR: International League of Associations for Rheumatology; RF: rheumatoid factor; SF-12: SF-12v2 Health Survey; PCS: physical component summary; MCS: mental component summary; SCL-5: Hopkins Symptom Checklist 5; BPI: Brief Pain Inventory. 
Table 2. Changes over time in variables assessed at baseline and at 1-, 3-, and 19-year followup $(\mathrm{n}=96)$.

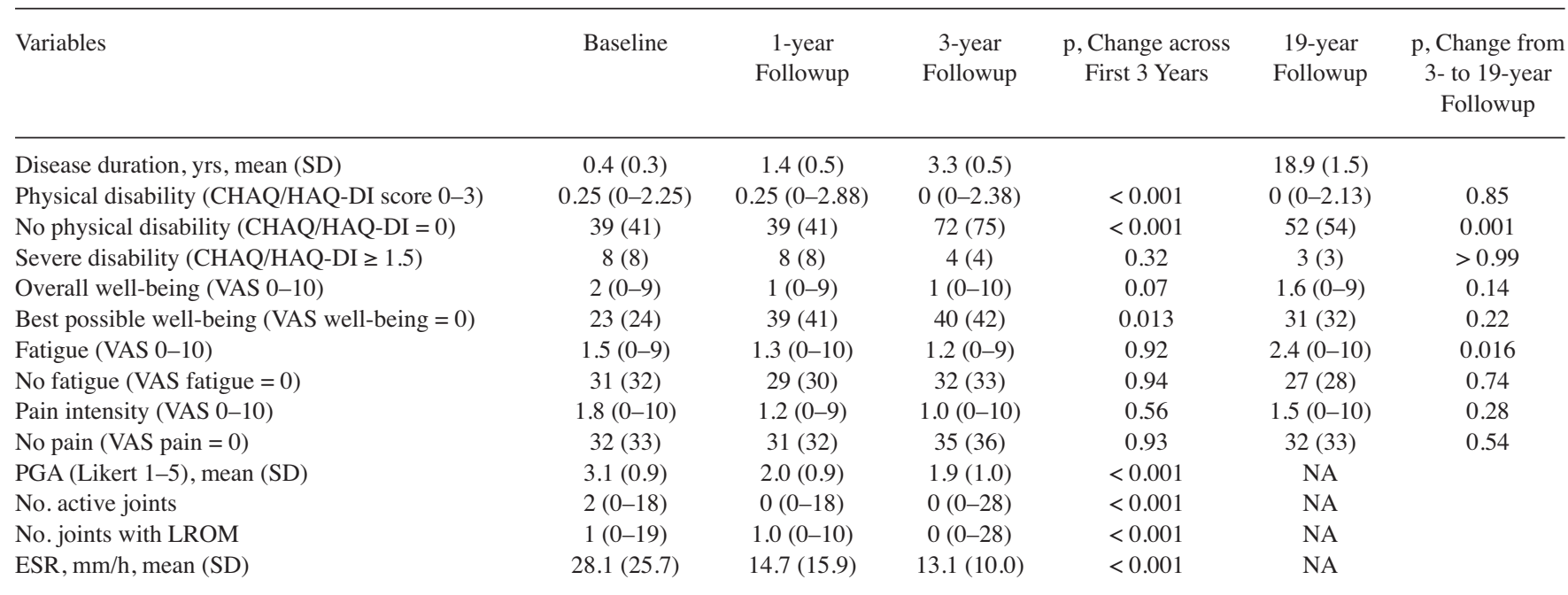

Values are median (range) or n (\%) unless otherwise indicated. CHAQ: Childhood Health Assessment Questionnaire; HAQ-DI: Health Assessment Questionnaire-Disability Index; VAS: visual analog scale; overall well-being: patient's global assessment of overall well-being; PGA: physician's global assessment of disease activity; LROM: limited range of motion; ESR: erythrocyte sedimentation rate; NA: not assessed.

and pain interference) were found in patients with JIA compared with controls $(\mathrm{p} \leq 0.001)$ and a higher percentage of patients reported moderate to severe fatigue (VAS fatigue $>3$ ) compared with controls $(\mathrm{p}=0.001$; Table 1$)$. Poorer physical HRQOL was found on the SF-12 PCS score and the subscales: role physical, bodily pain, general health, and vitality (all $\mathrm{p} \leq 0.001)$. HAQ-DI $>0$ and VAS pain were the most important correlates of reduced physical HRQOL as measured by the SF-12 PCS (Table 3). No differences were found between patients and controls regarding mental HRQOL as measured by the SF-12 MCS.

Disease-modifying antirheumatic drug (DMARD) use. Overall, 45 patients $(47 \%)$ had received biological DMARD (bDMARD) and 67 (70\%) had received MTX at some point during the followup period. In the first 3 years of followup, 7 patients $(7 \%)$ were treated with bDMARD and $52(54 \%)$ with MTX [including 4 (4\%) prior to baseline and $20(21 \%)$ since baseline]. At the 19 -year followup, 52 patients (54\%)

Table 3. Relationship between demographic and health-related variables assessed at 19-year followup and physical HRQOL measured by the SF-12 PCS in 96 patients with JIA.

Variables Physical HRQOL (SF-12 PCS) after 19 Years Univariate Analysis Multiple Regression Analysis *

\begin{tabular}{|c|c|c|c|c|}
\hline Variables assessed at 19-yr followup & $\mathrm{B}^{\dagger}(95 \% \mathrm{CI})$ & $\mathrm{p}$ & $\mathrm{B}^{\dagger}(95 \% \mathrm{CI})$ & $\mathrm{p}$ \\
\hline \multicolumn{5}{|l|}{ Patient demographics } \\
\hline Age, yrs & $0.2(-0.2,0.7)$ & 0.34 & & \\
\hline Mental HRQOL (SF-12 MCS) & $-0.1(-0.3,0.1)$ & 0.55 & & \\
\hline Physical limitations (HAQ-DI $>0$, range $0-3$ ) \# & $-11.0(-14.4,-7.6)$ & $<0.001$ & $-5.3(-8.3,-2.2)$ & 0.001 \\
\hline Pain intensity (VAS pain, range $0-10$ ) & $-2.5(-3.0,-2.0)$ & $<0.001$ & $-2.0(-2.6,-1.5)$ & $<0.001$ \\
\hline Anxiety and depression (SCL-5, range 0-4) & $-2.4(-5.2,-0.4)$ & 0.09 & & \\
\hline \multicolumn{5}{|l|}{ Clinical disease characteristics } \\
\hline No. active joints, self-reported & $-0.6(-1.0,-0.2)$ & 0.002 & & \\
\hline Current use of DMARD \# & $-2.9(-6.8,-1.1)$ & 0.10 & & \\
\hline Daily stiffness duration $>10 \mathrm{~min}$ & $-8.5(-12.1,-5.0)$ & $<0.001$ & & \\
\hline
\end{tabular}

$*$ Results from the final model of multiple linear regression analysis (backward regression method), $\mathrm{R}^{2}=58 \% .^{\dagger} \mathrm{B}$ : unstandardized regression coefficient.

\# Dichotomized variables. Brief Pain Inventory (pain intensity and pain interference) are not included in the analysis owing to multicollinearity with each other and with pain intensity (VAS pain). HRQOL: health-related quality of life; SF-12: SF-12v2 Health Survey; MCS: mental component summary; PCS: physical component summary; HAQ-DI: Health Assessment Questionnaire-Disability Index; VAS: visual analog scale; overall well-being: patient's global assessment of overall well-being; SCL-5: Hopkins Symptom Checklist 5; DMARD: disease-modifying antirheumatic drug. 
were using DMARD (Table 1). Of the $44(46 \%)$ not using DMARD, $6(6 \%)$ had used bDMARD and 24 (25\%) had used MTX within the last 10 years, but not at the 19-year followup. Comparisons of patients currently being treated with bDMARD (alone or in combination with synthetic DMARD; $\mathrm{n}=37$ ) and patients treated only with synthetic DMARD $(\mathrm{n}=15)$ indicated no significant differences in physical disability [HAQ-DI median 0.19 (range $0-2.13$ ) vs 0.13 (range $0-1.38$ ), pain (VAS pain median 1.7, range $0-10$ vs 1.1, range 0-8), and physical HRQOL (SF-12 PCS mean 46.9 \pm 11.3 vs $51.5 \pm 7.8)]$.

Changes in disease variables over time. During the first 3 years of followup, improvements were found in all disease activity variables $(\mathrm{p}<0.001)$. The level of physical disability (CHAQ/HAQ-DI) improved during the first 3 years $(\mathrm{p}<0.001)$, and the proportion of patients with no physical disability increased ( $<<0.001$; Table 2). Patients' experience of pain and fatigue did not change during the first 3 years, but the proportion of patients reporting best possible well-being increased $(p=0.013)$. Levels of physical disability, pain, and well-being were similar at 3- and 19-year followups, but the level of fatigue worsened $(\mathrm{p}=0.016)$ and the proportion of patients with no physical disability decreased $(\mathrm{p}=0.001)$.

Early predictors of physical limitation, pain, and physical HRQOL after 19 years. Results from the univariate analyses showed that pain at baseline and both PGA and CHAQ $\geq 1$ at 3 years were associated with physical limitations (HAQ-DI $>0$ ) at the 19-year followup ( $\mathrm{p}=0.007-0.037$; Table 4). Pain intensity after 19 years was associated with age and number of active joints, ESR, CHAQ $\geq 1$, and VAS pain at baseline, and $C H A Q \geq 1$ at 3 years $(p<0.001-0.02)$. Number of active joints, ESR, CHAQ $\geq 1$, pain, and patient's overall well-being at baseline, as well as PGA, presence of active joints, CHAQ $\geq 1$, and fatigue at 3 years were associated with physical HRQOL at the 19-year followup ( $p<0.001-0.044$ ).

In the multivariate analyses (adjusted for age and sex), physical limitations (HAQ-DI >0) at 19-year followup were predicted by pain at baseline and physical disability (CHAQ $\geq 1)$ at 3 years $(\mathrm{p}=0.013-0.041$; Table 4$)$. Pain intensity at 19 -year followup was predicted by number of active joints and physical disability $(\mathrm{CHAQ} \geq 1)$ at baseline and physical disability $(\mathrm{CHAQ} \geq 1)$ at 3 years $(\mathrm{p}=0.001-0.013)$. Physical HRQOL (measured by SF-12 PCS) at 19-year followup was predicted by number of active joints and pain at baseline and presence of active joints and physical disability at 3 years ( $\mathrm{p}<0.001-0.047$ ).

Using GMM, 3 latent classes of pain within the first 3 years of disease duration were identified and named "recurrent pain" ( $\mathrm{n}=16 ; 17 \%)$, "late pain recovery" $(\mathrm{n}=10$; $10 \%)$, and "low pain" ( $\mathrm{n}=70 ; 73 \%$; Figure 1$)$. Late pain recovery during the early disease course was associated with physical disability (HAQ-DI $\geq 1$ ), more pain, and poorer physical HRQOL after 19 years $(\mathrm{p}=0.002-0.013$; Table 5$)$.

\section{DISCUSSION}

In our cohort of patients with JIA, the levels of physical disability (CHAQ/HAQ-DI), pain intensity, and overall well-being were similar at the 3- and 19-year followups, while fatigue worsened. After 19 years, patients had higher levels of pain severity and pain interference (measured by the BPI), poorer physical HRQOL (SF-12 PCS), and less work participation than controls from the general population. Pain intensity, active joints, and physical disability within the first 3 years of followup were early predictors of physical limitations, pain, and poorer physical HRQOL after 19 years. Further, late pain recovery during the first 3 years was associated with physical limitations, pain, and poorer HRQOL after 19 years.

Physical disability level, pain intensity, and overall well-being were similar, and fatigue was worse at the 19-year followup compared to the 3-year followup, despite improvements in JIA disease activity variables during the first 3 years of followup, as previously described ${ }^{22}$. Our results are in contrast to those of Zak, et al and Calabro, et al, who reported increased physical disability in their longitudinal followups of patients with JIA included in their studies in the 1960s and $1970 s^{14,35}$. Different methods used to assess disability may have influenced the results. In particular, it should be noted that physical disability was assessed using the CHAQ in childhood and HAQ-DI in adulthood, and although they measure the same concepts and have the same structure, they are not equivalent to each other and comparisons should be made with caution. Nonetheless, our results regarding stable physical disability level and pain between the 3- and 19-year followup are in accordance with more recent longitudinal longterm studies of JIA ${ }^{2,15}$. However, in contrast to our present study, a decline in overall well-being between 15 and 30 years of disease duration was found in another Norwegian cohort $^{6}$. We also found an increased level of fatigue between 3 - and 19-year followups. This finding is consistent with the study by Nijhof, et $a l^{36}$ who reported more fatigue with increasing age among adolescents with JIA, but it contradicts the study by Ostlie, et al, who found a stable level of fatigue between 9 - and 18 -year followups ${ }^{15}$. Fatigue is a multidimensional concept with various causes, for which potential mediators in young adults with JIA need to be explored further.

No physical disability (HAQ-DI $=0$ ) was found in $54 \%$ and severe disability (HAQ-DI $\geq 1.5$ ) in $3 \%$ of patients after 19 years. This frequency of HAQ-DI $=0$ is in line with several previous studies of adults with JIA $2,6,14,37,38$. Low frequencies of severe disability (HAQ-DI $\geq 1.5$ ) have also been reported in other more recent studies of longterm outcomes in JIA. Tollisen, et $a l^{6}$ reported HAQ-DI $\geq 1.5$ in $3 \%$ after 30 years in 2017 and Bertilsson, et al ${ }^{2}$ reported no patients with HAQ-DI $>1.5$ after 17 years in 2013. On the other hand, Minden, et al reported HAQ-DI $\geq 1$ in $7 \%$ after 17 years in 2002, and Ruperto, et al reported HAQ-DI > 1.5

Personal non-commercial use only. The Journal of Rheumatology Copyright @ 2019 . All rights reserved. 
Table 4A. The relationships of health- and disease-related variables assessed at baseline and after 3 years to physical limitations (HAQ-DI >0) after 19 years $(\mathrm{n}=96)^{*}$.

\begin{tabular}{|c|c|c|c|c|c|c|c|c|}
\hline \multirow[t]{2}{*}{$\begin{array}{l}\text { Health- and Disease- } \\
\text { related Variables }\end{array}$} & \multicolumn{2}{|c|}{$\begin{array}{l}\text { Univariate Analyses } \\
\text { with Baseline Predictors }\end{array}$} & \multicolumn{2}{|c|}{$\begin{array}{c}\text { Multiple Regression Analyses } \\
\text { with Baseline Predictors }\end{array}$} & \multicolumn{2}{|c|}{$\begin{array}{l}\text { Univariate Analyses with } \\
\text { 3-year Predictors }\end{array}$} & \multicolumn{2}{|c|}{$\begin{array}{c}\text { Multiple Regression Analyses } \\
\text { with 3-year Predictors }\end{array}$} \\
\hline & OR $(95 \% \mathrm{CI})$ & $\mathrm{p}$ & $\mathrm{OR}(95 \% \mathrm{CI})^{\mathrm{A}}$ & $\mathrm{p}$ & OR $(95 \% \mathrm{CI})$ & $\mathrm{p}$ & $\mathrm{OR}(95 \% \mathrm{CI})^{\mathrm{A}}$ & $\mathrm{p}$ \\
\hline Age at followup, yrs & $1.0(0.9-1.1)$ & 0.47 & $1.0(0.9-1.1)$ & 0.61 & $1.0(0.9-1.1)$ & 0.47 & $1.0(0.9-1.1)$ & 0.92 \\
\hline PGA $(1-5)$ & $1.2(0.7-1.9)$ & 0.43 & & & $1.9(1.2-3.0)$ & 0.007 & & \\
\hline Active joints 4 & $1.1(1.0-1.2)$ & 0.16 & & & $2.1(0.9-4.8)$ & 0.09 & & \\
\hline $\begin{array}{l}\text { Physical disability } \\
(\mathrm{CHAQ} \geq 1)^{* *}\end{array}$ & $1.5(0.5-4.3)$ & 0.45 & & & $7.8(1.6-38.0)$ & 0.011 & $7.8(1.5-39.3)$ & 0.013 \\
\hline Pain intensity (VAS 0-10) & $1.2(1.0-1.4)$ & 0.037 & $1.2(1.0-1.4)$ & 0.041 & $1.1(1.0-1.1)$ & 0.21 & & \\
\hline Fatigue (VAS 0-10) & $1.1(1.0-1.2)$ & 0.47 & & & $1.0(1.0-1.3)$ & 0.24 & & \\
\hline $\begin{array}{l}\text { Overall well-being } \\
\text { (VAS 0-10) }\end{array}$ & $1.1(1.0-1.4)$ & 0.15 & & & $1.2(1.0-1.4)$ & 0.08 & & \\
\hline
\end{tabular}

Table $4 B$. The relationships of health- and disease-related variables assessed at baseline and after 3 years to pain intensity $($ VAS pain $)$ after 19 years $(\mathrm{n}=96)^{\#}$.

\begin{tabular}{|c|c|c|c|c|c|c|c|c|}
\hline \multirow[t]{2}{*}{$\begin{array}{l}\text { Health- and Disease- } \\
\text { related Variables }\end{array}$} & \multicolumn{2}{|c|}{$\begin{array}{c}\text { Univariate Analyses } \\
\text { with Baseline Predictors }\end{array}$} & \multirow{2}{*}{\multicolumn{2}{|c|}{$\begin{array}{l}\text { Multiple Regression Analyses } \\
\text { with Baseline Predictors } \\
\mathrm{B}^{\dagger}(95 \% \mathrm{CI})^{\mathrm{B}}\end{array}$}} & \multicolumn{2}{|c|}{$\begin{array}{l}\text { Univariate Analyses with } \\
\text { 3-year Predictors }\end{array}$} & \multicolumn{2}{|c|}{$\begin{array}{c}\text { Multiple Regression Analyses } \\
\text { with 3-year Predictors }\end{array}$} \\
\hline & $\mathrm{B}^{\dagger}(95 \% \mathrm{CI})$ & $\mathrm{p}$ & & & $\mathrm{B}^{\dagger}(95 \% \mathrm{CI})$ & $\mathrm{p}$ & $\mathrm{B}^{\dagger}(95 \% \mathrm{CI})^{\mathrm{B}}$ & $\mathrm{p}$ \\
\hline Age at followup, yrs & $-0.1(-0.3,0.0)$ & 0.044 & $-0.1(-0.3,0)$ & 0.032 & $-0.1(-0.3,0.0)$ & 0.044 & $-0.1(-0.2,0.1)$ & 0.26 \\
\hline PGA (1-5) & $0.6(-0.1,1.2)$ & 0.07 & & & $0.4(-0.1,1.0)$ & 0.13 & & \\
\hline Active joints \#\# & $0.2(0.0-0.3)$ & 0.011 & $0.2(0.0-0.3)$ & 0.013 & $0.9(-0.3,2.0)$ & 0.14 & & \\
\hline $\begin{array}{l}\text { Physical disability } \\
(\mathrm{CHAQ} \geq 1)^{* *}\end{array}$ & $2.2(0.9-3.6)$ & 0.002 & $1.8(0.4-3.2)$ & 0.011 & $3.1(1.5-4.8)$ & $<0.001$ & $2.9(1.2-4.6)$ & 0.001 \\
\hline $\begin{array}{l}\text { Pain intensity } \\
\text { (VAS 0-10) }\end{array}$ & $0.3(0.0-0.1)$ & 0.020 & & & $0.0(-0.3,0.2)$ & 0.88 & & \\
\hline Fatigue (VAS $0-10$ ) & $0.1(-0.1,0.3)$ & 0.26 & & & $0.1(-0.1,0.3)$ & 0.39 & & \\
\hline $\begin{array}{l}\text { Overall well-being } \\
\text { (VAS 0-10) }\end{array}$ & $0.2(0.0-0.5)$ & 0.08 & & & $0.1(-0.2,0.3)$ & 0.64 & & \\
\hline
\end{tabular}

Table 4C. The relationships of health- and disease-related variables assessed at baseline and after 3 years to physical HRQOL (SF-12 PCS) after 19 years ( $\mathrm{n}=96)^{\#}$.

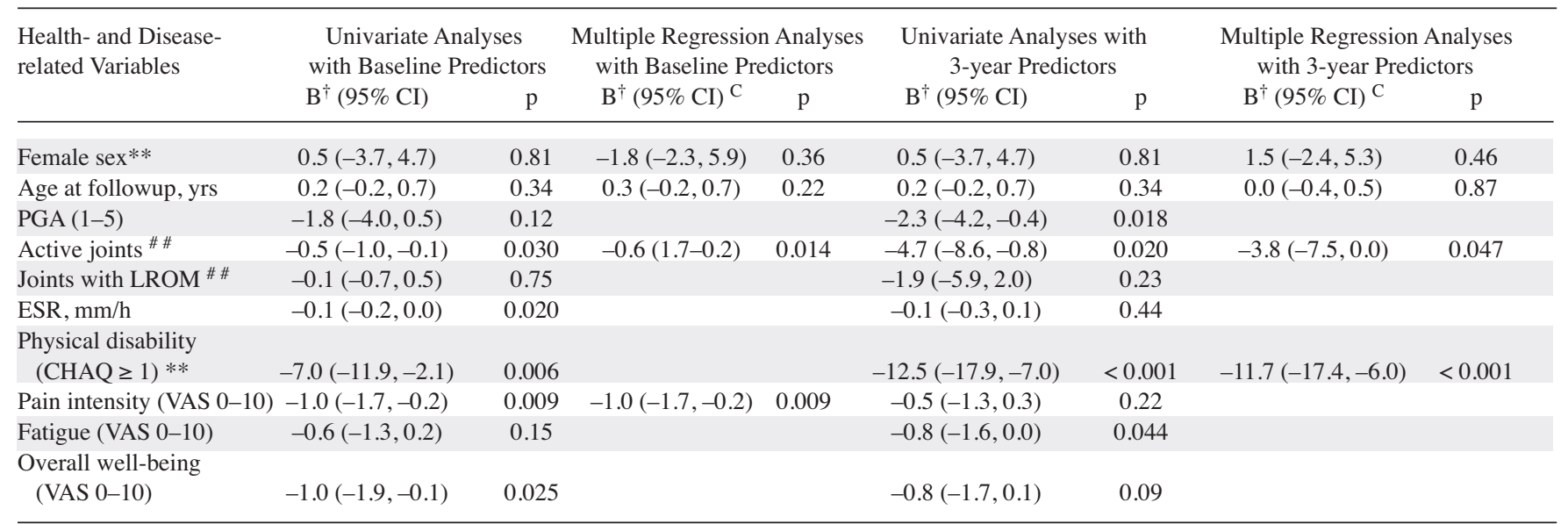

* Logistic regression analyses. ${ }^{\#}$ Linear regression analyses. ${ }^{\dagger} \mathrm{B}$ : unstandardized regression coefficient. ${ }^{\mathrm{A}}$ Nagelkerke $\mathrm{R}^{2}$ at baseline: $8 \%$, after 3 years: $13 \%$. ${ }^{\mathrm{B}} \mathrm{R}^{2}$ at baseline $=18 \%$, after 3 years $=15 \% .{ }^{\mathrm{C}} \mathrm{R}^{2}$ at baseline $=14 \%$, after 3 years $=22 \%$. ** Dichotomized variable. ${ }^{\# \#}$ Total no. at baseline and dichotomized (no. joints with active arthritis $=0$ ) at 3 -year followup. ${ }^{4}$ Discrete numerical variables at baseline and dichotomized (no joints with active arthritis 0 value of $=$ 0 ) at 3-year followup. HAQ-DI: Health Assessment Questionnaire-Disability Index; VAS: visual analog scale; HRQOL: health-related quality of life; SF-12: SF-12v2 Health Survey; PCS: physical component summary; PGA: physician's global assessment of disease activity; LROM: limited range of motion; ESR: erythrocyte sedimentation rate; CHAQ: Childhood Health Assessment Questionnaire; Overall well-being: patient's global assessment of overall well-being. 


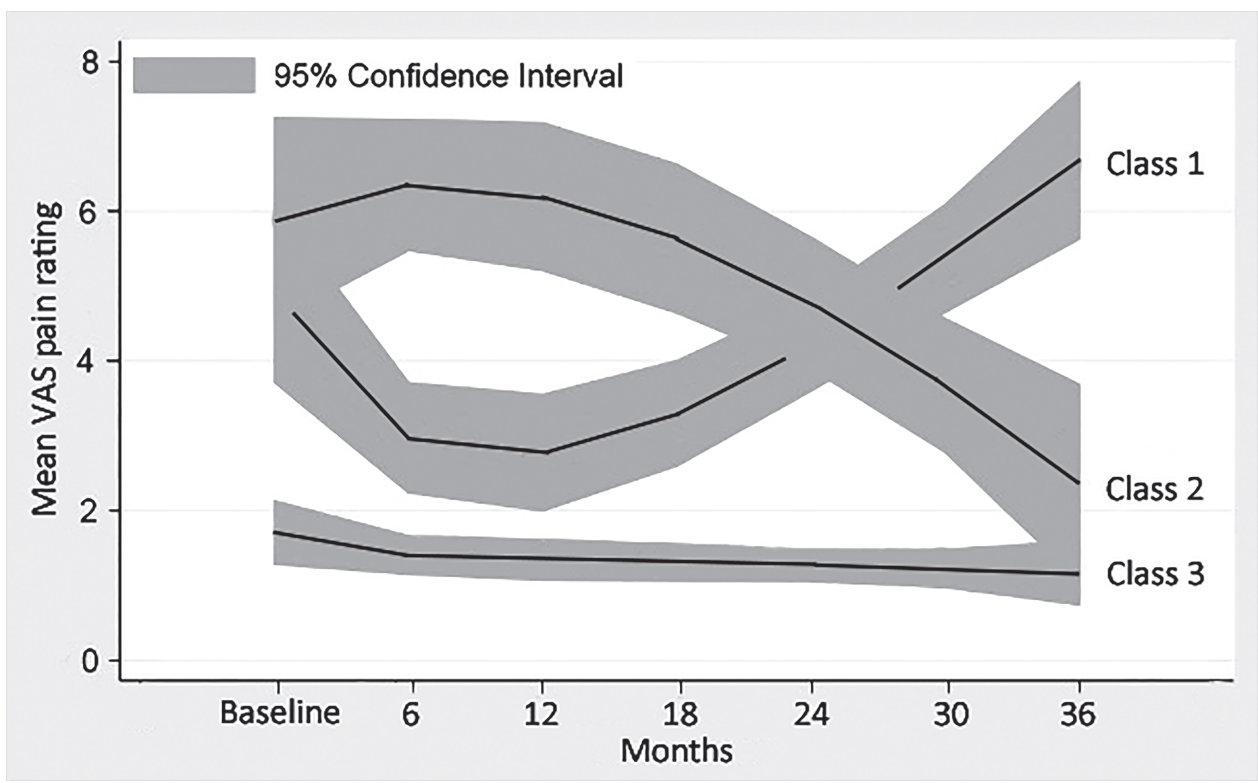

Figure 1. Trajectories of pain assessed every 6 months for 3 years at early disease course. Class $1=$ recurrent pain, $\mathrm{n}=16(17 \%)$. Class $2=$ late pain recovery, $\mathrm{n}=10(10 \%)$. Class $3=$ low pain, $\mathrm{n}=70(73 \%)$. VAS: visual analog scale.

Table 5. Multiple regression models examining pain trajectory group membership early in the disease course as a predictor of physical disability, pain intensity, and physical HRQOL at 19-year followup $(n=96) *$.

\begin{tabular}{|c|c|c|c|}
\hline \multirow[t]{2}{*}{ Variables } & \multicolumn{3}{|c|}{ Physical Disability (HAQ-DI $\geq 1$ ) after 19 Years } \\
\hline & OR & $95 \% \mathrm{CI}$ & $\mathrm{p}$ \\
\hline Patients with recurrent pain vs low pain & 5.8 & $1.0,34.4$ & 0.053 \\
\hline \multirow[t]{3}{*}{ Patients with late pain recovery vs low pain } & 10.7 & $1.6,69.7$ & 0.013 \\
\hline & \multicolumn{3}{|c|}{ Pain Intensity (VAS Pain) after 19 Years $* *$} \\
\hline & $\mathrm{B}^{\dagger}$ & $95 \% \mathrm{CI}$ & $\mathrm{p}$ \\
\hline Patients with recurrent pain vs low pain & 0.1 & $-1.3,1.6$ & 0.85 \\
\hline \multirow[t]{2}{*}{ Patients with late pain recovery vs low pain } & 2.6 & $0.7-4.4$ & 0.006 \\
\hline & \multicolumn{3}{|c|}{ Physical HRQOL (SF-12 PCS) after 19 Years ** } \\
\hline Patients with recurrent pain vs low pain & -4.0 & $-9.2,1.2$ & 0.13 \\
\hline Patients with late pain recovery vs low pain & -10.1 & $-16.4,-3.8$ & 0.002 \\
\hline
\end{tabular}

* Adjusted for age at 19-year followup and sex. ${ }^{\#}$ Logistic regression analysis. ** Linear regression analyses. ${ }^{\dagger} \mathrm{B}$ : unstandardized regression coefficient. HRQOL: health-related quality of life; VAS: visual analog scale; HAQ-DI: Health Assessment Questionnaire-Disability Index; SF-12: SF-12v2 Health Survey; PCS: physical component summary.

in $4 \%$ after 15 years in $1997^{39,40}$. Measured by the Steinbrocker method, severe disability was present in $3 \%$ in a study published in 2002, and $15-17 \%$ in cohorts described around $1990^{35,38,41}$. Our results support that there has been a decline in the frequency of severe disability in adults with JIA during the last 2 decades.

A total of $27 \%$ of patients reported moderate to severe pain (VAS > 3) after 19 years and the patients in our study had higher scores on pain severity and effect of pain on daily functioning (assessed by BPI) than age- and sex-matched controls. Our study tends to confirm that pain is an important dimension of the burden of the disease in patients with JIA, which is also supported by other publications ${ }^{11,12,42}$.

Adult patients with JIA had poorer physical HRQOL than controls, while mental health status and academic achievement were similar; these findings are consistent with those of other studies $2,6,7,8,19$. We found less work participation in our patients compared to controls. Occupational outcomes in adults with a history of JIA have varied in previous studies $^{6,7,38,39,43,44,45}$, and differences in the social insurance system and level of disease severity among the study populations may influence these differences.

Physical disability (CHAQ $\geq 1)$ at baseline predicted more pain at 19-year followup, and CHAQ $\geq 1$ at 3 years predicted physical limitations, lower physical HRQOL, and more pain at 19 years. Number of active joints at baseline predicted more pain and lower physical HRQOL, while presence of active joints at 3 years predicted lower physical HRQOL at

Personal non-commercial use only. The Journal of Rheumatology Copyright @ 2019 . All rights reserved. 
19 years. Bertilsson, et al found no significant baseline predictors of physical disability after 17 years $^{2}$. However, similar to our study, they found an association between CHAQ at 5 years and physical limitations at 17 years, as well as associations between number of joints with arthritis and CHAQ at 5-year followup and physical HRQOL at 17 years ${ }^{2}$. Identification of early prognostic factors of longterm outcomes in JIA has been difficult ${ }^{20}$, and the value of physical disability and active joints early in the disease course for predictions of later health status warrants further study.

Pain intensity at baseline predicted physical limitations (HAQ-DI > 0) and lower physical HRQOL at 19-year followup. During the first 3 years of followup, 3 different pain trajectories were identified within this patient group. We found associations between late pain recovery early in the disease course and physical disability, pain, and physical HRQOL at the 19-year followup. It should however be taken into account that the group of patients demonstrating late pain recovery is small $(n=10)$ and further studies with larger samples are required. The longterm effect of pain in JIA has not been well studied, despite pain being considered a main symptom of JIA ${ }^{12,25,46}$. The pathogenesis of pain in children with JIA is multifactorial and not fully understood, hence regular pain assessment and treatment should be promoted in clinical practice ${ }^{47,48}$.

This study has some limitations. No assessments were done between the 3- and 19-year followups and no clinical examinations were performed at the 19-year followup; therefore, results should be interpreted with caution. Moreover, we do not have information regarding remission status among the participating patients, although 54\% of the patients were currently being treated with synthetic and/or bDMARD at 19-year followup. Also, 59\% of the patients reported active joints (self-reported pain or swelling in combination with LROM), but this result should also be interpreted with caution. Dijkstra, et al reported a patient tendency to overestimate the presence of active joints, although patient indication of absence of arthritis proved to be highly reliable ${ }^{34}$. It should also be noted that patients in our cohort were diagnosed in the prebiologic era, since biologic treatments were introduced to patients with JIA in 2000. Although only 7 patients used bDMARD during the first 3 years, $67 \%$ of our patients received bDMARD at some time during the 19-year followup period.

The patients in our cohort are referral-based, hence there was an increased probability for participants with more severe disease compared to population-based cohorts. However, the patients were comparable to patients with JIA in a number of epidemiological studies regarding sex, age at onset, and distribution of diagnostic subgroups $2,8,49,50$. Additionally, at baseline no significant differences were found between the participants and nonparticipants regarding age, sex, and disease subtype. The healthcare system in Norway is largely tax-funded with equal access to specialist care for all patients with JIA, which also increases the probability of a patient being included regardless of disease activity level.

This study, with its longitudinal and prospective design, adds valuable information to the scarce data on longterm patient-reported outcomes of patients treated with synthetic and/or biological DMARD early in the disease course. Similar levels of physical disability, pain, and well-being were found at 3- and 19-year followup, but patients reported more fatigue and a lower percentage reported no physical disability after 19 years. JIA has a detrimental effect on physical disability, pain, and physical HRQOL 19 years after disease onset. The early predictors in our study were pain, physical disability (CHAQ $\geq 1)$, and active joints at baseline and/or at 3 years. Late pain recovery early in the disease course was associated with poorer health status after 19 years. However, further studies are required to explore early predictors of patient-reported outcomes in adults with JIA.

\section{ACKNOWLEDGMENT}

We thank Leiv Sandvik and Magne Thoresen (Institute of Basic Medical Science, Faculty of Medicine, Oslo University, Oslo, Norway) for statistical support; Thorhild Garen, Trude Ingebrigtsen (Department of Rheumatology, Oslo University Hospital), and Gunn-Helen Malmstrøm (Unger-Vetlesens Institutt, Lovisenberg Diaconal Hospital) for technical assistance; Caryl Gay (University of California/Lovisenberg Diaconal Hospital) for useful comments on the manuscript; and Joachim Sagen (Children and Youth Rheumatology Association) for useful comments on the questionnaires.

\section{REFERENCES}

1. Selvaag AM, Aulie HA, Lilleby V, Flatø B. Disease progression into adulthood and predictors of long-term active disease in juvenile idiopathic arthritis. Ann Rheum Dis 2016;75:190-5

2. Bertilsson L, Andersson-Gäre B, Fasth A, Petersson IF, Forsblad-D'elia H. Disease course, outcome, and predictors of outcome in a population-based juvenile chronic arthritis cohort followed for 17 years. J Rheumatol 2013;40:715-24.

3. Dimopoulou D, Trachana M, Pratsidou-Gertsi P, Sidiropoulos P, Kanakoudi-Tsakalidou F, Dimitroulas T, et al. Predictors and long-term outcome in Greek adults with juvenile idiopathic arthritis: a 17-year continuous followup study. Rheumatology 2017; 56:1928-38.

4. Barth S, Haas JP, Schlichtiger J, Molz J, Bisdorff B, Michels H, et al. Long-term health-related quality of life in German patients with juvenile idiopathic arthritis in comparison to German general population. PLoS One 2016;11:e0153267.

5. World Health Organization. Basic documents. [Internet. Accessed May 15, 2019.] Available from: apps.who.int/gb/bd/PDF/bd48/basic-documents-48th-edition-en.pdf

6. Tollisen A, Selvaag AM, Aulie HA, Lilleby V, Aasland A, Lerdal A, et al. Physical functioning, pain, and health-related quality of life in adults with juvenile idiopathic arthritis: a longitudinal 30-year followup study. Arthritis Care Res 2018;70:741-9.

7. Foster HE, Marshall N, Myers A, Dunkley P, Griffiths ID. Outcome in adults with juvenile idiopathic arthritis: a quality of life study. Arthritis Rheum 2003;48:767-75.

8. Peterson LS, Mason T, Nelson AM, O'Fallon WM, Gabriel SE. Psychosocial outcomes and health status of adults who have had juvenile rheumatoid arthritis: a controlled, population-based study. Arthritis Rheum 1997;40:2235-40. 
9. Packham JC, Hall MA, Pimm TJ. Long-term followup of 246 adults with juvenile idiopathic arthritis: predictive factors for mood and pain. Rheumatology 2002;41:1444-9.

10. Horneff G, Schulz AC, Klotsche J, Hospach A, Minden K, Foeldvari $\mathrm{I}$, et al. Experience with etanercept, tocilizumab and interleukin-1 inhibitors in systemic onset juvenile idiopathic arthritis patients from the BIKER registry. Arthritis Res Ther 2017;19:256.

11. Anink J, Prince FH, Dijkstra M, Otten MH, Twilt M, ten Cate R, et al. Long-term quality of life and functional outcome of patients with juvenile idiopathic arthritis in the biologic era: a longitudinal follow-up study in the Dutch Arthritis and Biologicals in Children Register. Rheumatology 2015;54:1964-9.

12. Bromberg MH, Connelly M, Anthony KK, Gil KM, Schanberg LE. Self-reported pain and disease symptoms persist in juvenile idiopathic arthritis despite treatment advances: an electronic diary study. Arthritis Rheumatol 2014;66:462-9.

13. Minden K, Niewerth M, Zink A, Seipelt E, Foeldvari I, Girschick H, et al. Long-term outcome of patients with JIA treated with etanercept, results of the biologic register JuMBO. Rheumatology 2012;51:1407-15.

14. Zak M, Pedersen FK. Juvenile chronic arthritis into adulthood: a long-term followup study. Rheumatology 2000;39:198-204.

15. Ostlie IL, Aasland A, Johansson I, Flato B, Moller A. A longitudinal followup study of physical and psychosocial health in young adults with chronic childhood arthritis. Clin Exp Rheumatol 2009;27:1039-46.

16. Albers HM, Brinkman DM, Kamphuis SS, van Suijlekom-Smit LW, van Rossum MA, Hoppenreijs EP, et al. Clinical course and prognostic value of disease activity in the first two years in different subtypes of juvenile idiopathic arthritis. Arthritis Care Res 2010;62:204-12.

17. Flatø B, Aasland A, Vinje O, Førre O. Outcome and predictive factors in juvenile rheumatoid arthritis and juvenile spondyloarthropathy. J Rheumatol 1998;25:366-75.

18. Oen K, Malleson PN, Cabral DA, Rosenberg AM, Petty RE, Reed $\mathrm{M}$, et al. Early predictors of longterm outcome in patients with juvenile rheumatoid arthritis: subset-specific correlations. J Rheumatol 2003;30:585-93

19. Flatø B, Lien G, Smerdel A, Vinje O, Dale K, Johnston V, et al. Prognostic factors in juvenile rheumatoid arthritis: a case-control study revealing early predictors and outcome after 14.9 years. J Rheumatol 2003;30:386-93.

20. Ravelli A, Martini A. Early predictors of outcome in juvenile idiopathic arthritis. Clin Exp Rheumatol 2003;21:S89-93.

21. Wallace CA, Huang B, Bandeira M, Ravelli A, Giannini EH Patterns of clinical remission in select categories of juvenile idiopathic arthritis. Arthritis Rheum 2005;52:3554-62.

22. Selvaag AM, Lien G, Sørskaar D, Vinje O, Førre Ø, Flatø B. Early disease course and predictors of disability in juvenile rheumatoid arthritis and juvenile spondyloarthropathy: a 3 year prospective study. J Rheumatol 2005;32:1122-30.

23. Oen K, Duffy CM, Tse SM, Ramsey S, Ellsworth J, Chedeville G, et al. Early outcomes and improvement of patients with juvenile idiopathic arthritis enrolled in a Canadian multicenter inception cohort. Arthritis Care Res 2010;62:527-36

24. Rashid A, Cordingley L, Carrasco R, Foster HE, Baildam EM, Chieng A, et al. Patterns of pain over time among children with juvenile idiopathic arthritis. Arch Dis Child 2018;103:437-43.

25. Tupper SM, Rosenberg AM, Pahwa P, Stinson JN. Pain intensity variability and its relationship with quality of life in youths with juvenile idiopathic arthritis. Arthritis Care Res 2013;65:563-70.

26. Petty R, Cassidy J. Chronic arthritis in childhood. In: Cassidy JT, Petty RE, Laxer RM, Lindsley CB, editors. Textbook of pediatric rheumatology. Philadelphia: Elsevier Saunders; 2011:211-35.

27. Singh G, Athreya BH, Fries JF, Goldsmith DP. Measurement of health status in children with juvenile rheumatoid arthritis. Arthritis Rheum 1994;37:1761-9.

28. Wewers ME, Lowe NK. A critical review of visual analogue scales in the measurement of clinical phenomena. Res Nurs Health 1990;13:227-36.

29. Giannini EH, Ruperto N, Ravelli A, Lovell DJ, Felson DT, Martini A. Preliminary definition of improvement in juvenile arthritis. Arthritis Rheum 1997;40:1202-9.

30. Ware J Jr, Kosinski M, Keller SD. A 12-item short-form health survey: construction of scales and preliminary tests of reliability and validity. Med Care 1996;34:220-33.

31. Cleeland CS, Ryan KM. Pain assessment: global use of the Brief Pain Inventory. Ann Acad Med Singapore 1994;23:129-38.

32. Tambs K, Moum T. How well can a few questionnaire items indicate anxiety and depression? Acta Psychiatr Scand 1993; 87:364-7.

33. Fries JF, Spitz P, Kraines RG, Holman HR. Measurement of patient outcome in arthritis. Arthritis Rheum 1980;23:137-45.

34. Dijkstra ME, Anink J, van Pelt PA, Hazes JM, van Suijlekom-Smit LW. Patient-reported joint count in juvenile idiopathic arthritis: the reliability of a manikin format. J Rheumatol 2015;42:527-33.

35. Calabro JJ, Marchesano JM, Parrino GR. Juvenile rheumatoid arthritis: long-term management and prognosis. J Musculoskel Med 1989;6:17-32.

36. Nijhof LN, van de Putte EM, Wulffraat NM, Nijhof SL. Prevalence of severe fatigue among adolescents with pediatric rheumatic diseases. Arthritis Care Res 2016;68:108-14.

37. Minden K, Niewerth M, Listing J, Biedermann T, Bollow M, Schontube M, et al. Long-term outcome in patients with juvenile idiopathic arthritis. Arthritis Rheum 2002;46:2392-401.

38. Oen K, Malleson PN, Cabral DA, Rosenberg AM, Petty RE, Cheang M. Disease course and outcome of juvenile rheumatoid arthritis in a multicenter cohort. J Rheumatol 2002;29:1989-99.

39. Minden K, Kiessling U, Listing J, Niewerth M, Doring E, Meincke $\mathrm{J}$, et al. Prognosis of patients with juvenile chronic arthritis and juvenile spondyloarthropathy. J Rheumatol 2000;27:2256-63.

40. Ruperto N, Levinson JE, Ravelli A, Shear ES, Link Tague B, Murray K, et al. Long-term health outcomes and quality of life in American and Italian inception cohorts of patients with juvenile rheumatoid arthritis. I. Outcome status. J Rheumatol 1997; 24:945-51.

41. Levinson JE, Wallace CA. Dismantling the pyramid. J Rheumatol Suppl. 1992 Apr;33:6-10.

42. Lomholt JJ, Thastum M, Herlin T. Pain experience in children with juvenile idiopathic arthritis treated with anti-TNF agents compared to non-biologic standard treatment. Pediatr Rheumatol Online J 2013;11:21

43. Packham JC, Hall MA. Long-term followup of 246 adults with juvenile idiopathic arthritis: education and employment Rheumatology 2002;41:1436-9.

44. Diaz-Mendoza AC, Modesto Caballero C, Navarro-Cendejas J. Analysis of employment rate and social status in young adults with childhood-onset rheumatic disease in Catalonia. Pediatr Rheumatol Online J 2015;13:29.

45. Schlichtiger J, Haas JP, Barth S, Bisdorff B, Hager L, Michels H, et al. Education and employment in patients with juvenile idiopathic arthritis - a standardized comparison to the German general population. Pediatr Rheumatol Online J 2017; 15:45

46. Weiss JE, Luca NJ, Boneparth A, Stinson J. Assessment and management of pain in juvenile idiopathic arthritis. Paediatr Drugs 2014;16:473-81.

47. Anthony KK, Schanberg LE. Pain in children with arthritis: a review of the current literature. Arthritis Rheum 2003;49:272-9.

48. Stinson JN, Luca NJ, Jibb LA. Assessment and management of pain in juvenile idiopathic arthritis. Pain Res Manag 2012;17:391-6.

Personal non-commercial use only. The Journal of Rheumatology Copyright @ $\odot$ 2019. All rights reserved 
49. Berntson L, Andersson Gare B, Fasth A, Herlin T, Kristinsson J, Lahdenne $\mathrm{P}$, et al. Incidence of juvenile idiopathic arthritis in the Nordic countries. A population based study with special reference to the validity of the ILAR and EULAR criteria. J Rheumatol 2003;30:2275-82.
50. Modesto C, Anton J, Rodriguez B, Bou R, Arnal C, Ros J, et al. Incidence and prevalence of juvenile idiopathic arthritis in Catalonia (Spain). Scand J Rheumatol 2010;39:472-9.

APPENDIX 1. Participant flow chart.

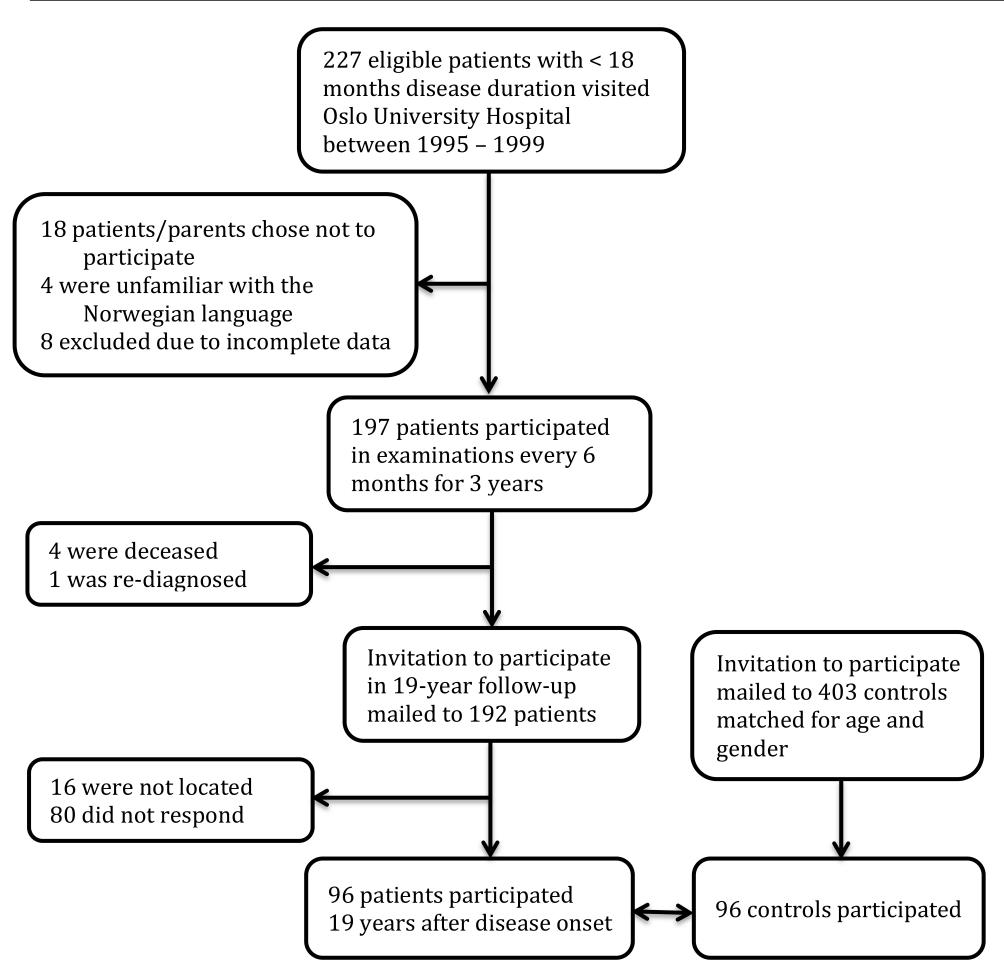

